Original Article

\title{
Effects of perioperative factors and hip geometry on hip abductor muscle strength during the first 6 months after anterolateral total hip arthroplasty
}

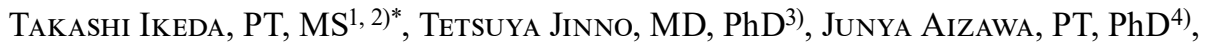
Tadashi Masuda, PhD ${ }^{5)}$, Kazuo Hirakawa, MD, PhD $^{6}$, Kazunari Ninomiya, PT $^{6}$, Kouji Suzuki, $\mathrm{PT}^{6}$, SAdao Morita, MD, PhD ${ }^{1)}$

1) Department of Rehabilitation Medicine, Tokyo Medical and Dental University Graduate School: 1-5-45 Yushima, Bunkyo-ku, Tokyo 113-8510, Japan

2) Showa University School of Nursing and Rehabilitation Sciences, Japan

3) Department of Joint Surgery and Sports Medicine, Tokyo Medical and Dental University Graduate School, Japan

4) Clinical Center for Sports Medicine \& Sports Dentistry, Tokyo Medical and Dental University, Japan

5) Faculty of Symbiotic Systems Science, Fukushima University, Japan

6) Shonan Kamakura Joint Reconstruction Center, Japan

\begin{abstract}
Purpose] The importance and effect of hip joint geometry on hip abductor muscle strength are well known. In addition, other perioperative factors are also known to affect hip abductor muscle strength. This study examined the relative importance of factors affecting hip abductor muscle strength after total hip arthroplasty. [Subjects and Methods] The subjects were 97 females with osteoarthritis scheduled for primary unilateral THA. The following variables were assessed preoperatively and 2 and 6 months after surgery: isometric hip abductor strength, radiographic analysis (Crowe class, postoperative femoral offset (FO)), Frenchay Activities Index, compliance rate with home exercise, Japanese Orthopaedic Association Hip-Disease Evaluation Questionnaire (JHEQ), and demographic data. Factors related to isometric hip abductor muscle strength 2 and 6 months after surgery were examined. [Results] Significant factors related to isometric hip abductor muscle strength at 2 and 6 months after surgery were, in extraction order: 1 . isometric hip abductor muscle strength in the preoperative period; 2. BMI; and 3. the JHEQ mental score at 2 and 6 months after surgery. [Conclusion] Preoperative factors and postoperative mental status were related to postoperative isometric hip abductor strength. FO was not extracted as a significant factor related to postoperative isomeric hip abductor strength.

Key words: Hip muscle strength, Femoral offset, Mental status
\end{abstract}

(This article was submitted Oct. 19, 2016, and was accepted Nov. 7, 2016)

\section{INTRODUCTION}

Total hip arthroplasty (THA) is widely performed for the purpose of alleviating pain and improving activities of daily living (ADLs). It is important to repair the hip center and lever arm that cause decreased mechanical efficiency due to hip deformity and to improve mechanical efficiency when reconstructing hip joint function ${ }^{1,2}$. Hip abductor muscle strength after THA is known to be affected by the height of the hip center ${ }^{3-5)}$, femoral offset (FO), and the gluteus medius lever arm ${ }^{1,5)}$. Asayama and Chamnnongkich ${ }^{5}$ examined osteoarthritis (OA) patients with at least 1.6 years of postoperative follow-up after

*Corresponding author. Takashi Ikeda (E-mail: ikereh@tmd.ac.jp; tk.ikeda@nr.showa-u.ac.jp)

(C2017 The Society of Physical Therapy Science. Published by IPEC Inc.

This is an open-access article distributed under the terms of the Creative Commons Attribution Non-Commercial No Derivatives (by-nc-nd) License $<$ http://creativecommons.org/licenses/by-nc-nd/4.0/>. 
THA, and they demonstrated that the ratio of hip abductor muscle strength of the reconstructed side to that of the unoperated side was strongly and positively correlated with the ratio of FO to body weight lever arm and negatively correlated with the height of the hip center.

Concerning THA and leg strength, it has been shown in patients scheduled for THA that preoperative hip abductor muscle strength is $31 \%$ less than that in healthy individuals, and that preoperative hip abductor muscle strength is not correlated with physical activity ${ }^{6}$. Additionally, hip abductor muscle strength and total workload at 5 months after THA are 56\% and 20\% of the levels of community dwelling elderly people, respectively, indicating a marked difference between the patients with THA and elderly people ${ }^{7)}$. Moreover, patients who have undergone THA have residual muscle atrophy of the quadriceps and do not show recovery in quadriceps muscle strength ${ }^{8}$. Furthermore, it has also been reported that the hip abductor muscle strength on the reconstructed side only recovers to about $80 \%$ of that on the unoperated side at both 6 months and 2 years postoperatively ${ }^{9}$. In patients with unilateral developmental dysplasia of the hip (DDH) scheduled to undergo THA, Liu and $W^{10)}$ reported that cross-sectional area of the gluteus medius was significantly smaller, and that the FO and gluteus medius lever arm were also significantly decreased on the reconstructed side vs. the unoperated side; they speculated that a greater length of time may be required for postoperative muscle strength recovery when considering the changes in gluteus medius. Clinically, even though the artificial joint placement site and the lever arm are properly configured, many patients have a prolonged decrease in muscle strength. Previous studies ${ }^{6-10)}$ have demonstrated that hip abductor muscle strength does not recover to the level of the unoperated side or of older people in the geographic region at 5 to 6 months after THA surgery, and it has therefore been postulated that multiple factors aside from mechanical factors are involved in the prolonged decrease of muscle strength. The purpose of this study was to compare the artificial joint lever arm, which is a mechanical factor related to postoperative hip abductor muscle strength, and other factors that are considered to potentially affect postoperative hip abductor muscle strength, including preoperative hip abductor muscle strength, the amount of subluxation of the hip, age $^{11,12)}$, body mass index $(\mathrm{BMI})^{11,12)}$, duration of disease ${ }^{13)}$, physical activity ${ }^{6,12)}$, compliance rate with exercise, and mental state $^{14,16)}$, and to elucidate the relative importance of factors affecting hip abductor muscle strength during the first 6 months after surgery.

\section{SUBJECTS AND METHODS}

A total of 103 females with osteoarthritis scheduled for primary unilateral total hip arthroplasty were eligible. All surgeries were performed by, or under the supervision of, one co-author $(\mathrm{KH})$. The anterolateral approach was used for all patients. This procedure was reported by Berger ${ }^{17)}$. The procedure takes off $20-25 \%$ of the gluteus medius and uses a shorter incision. The skin incision was less than 10-cm long. After setting the femoral and acetabular components, the gluteus medius and the gluteus minimus were completely re-attached to the greater trochanter. Exclusion criteria were as follows: patients with Charnley classes B and C; rheumatoid arthritis; osteonecrosis; previous surgery on the affected hip; disorders of the nervous system and muscles; depression; or a schizophrenic disorder. Recruitment was conducted at the Shonan Joint Reconstruction Center from May 3, 2013 to February 6, 2014. The follow-up was conducted 2 and 6 months after surgery from August 3, 2013 to September 6, 2014. The Tokushukai Group Ethics Committee approved the study protocol (ID: TGE00304-115). The intervention procedures were fully explained to all participants, and their written, informed consent was obtained. There were not any financial and personal relationships with other people or organizations that could inappropriately influence or bias present work.

The patients were permitted full-weight bearing on the day of surgery, but compound motion of the hip (combined hip flexion $90^{\circ}$, hip adduction, and hip internal rotation) was contraindicated to prevent dislocation of the hip. The standard physical therapy pathway involved patients ambulating with a walker-cane on the morning after surgery, a single cane on postoperative day (POD) 3, and ascending and descending stairs on POD 5. Patients who were able to walk with a single cane and ascend and descend stairs independently were discharged home.

Evaluations were conducted in the preoperative period and 2 and 6 months after surgery. Investigators determined muscle strength (isometric hip abductor strength), radiographic analyses (Crowe class, postoperative femoral offset (FO), height of the hip center (HC)), Frenchay Activities Index (FAI), compliance rate with home exercise, and the Japanese Orthopaedic Association Hip-Disease Evaluation Questionnaire (JHEQ). Demographic data were collected from clinical records and included: age, body mass index (BMI), diagnosis, disease duration, co-morbidity index, and the Harris hip score.

Isometric hip abductor strength measurements were performed in all patients using a handheld dynamometer (MicroFET2, Hoggan Health Industries, Salt Lake City, UT, USA) in the supine position. A handheld dynamometer was placed lateral to the fibula $2.5 \mathrm{~cm}$ proximal to the malleolus. The torque and body weight ratio $(\mathrm{Nm} / \mathrm{kg})$ were measured using the spina malleolar distance and body weight. Three trials at maximum effort were performed, and the highest value was used for the analysis.

Anteroposterior radiographs of the pelvis were taken on the day of examination preoperatively and 2 months after surgery. The amount of hip subluxation in the preoperative period was evaluated using the Crowe class ${ }^{18)}$, and quantitative assessment was also performed (Crowe \%). Using the inferior margin of each tear drop as the reference line, the ratio of the distance from the reference line to the top of the femoral head on the unaffected side and the distance from the reference line to the head neck junction on the affected side was calculated (Fig. 1). For convenience, primary hip osteoarthritis was treated as Crowe 


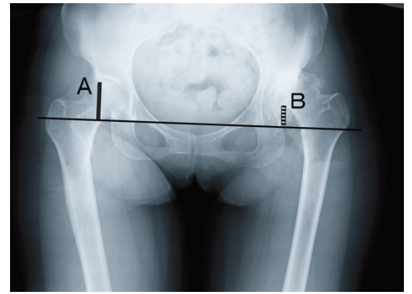

Fig. 1. Crowe class

Using the inferior margin of each tear drop as the reference line, the ratio of the distance from the reference line to the top of the femoral head on the unaffected side (A: solid bar) and the distance from the reference line to the head neck junction on the affected side (B: stripe bar) was calculated $(\mathrm{B} / \mathrm{A} \times 100)$.

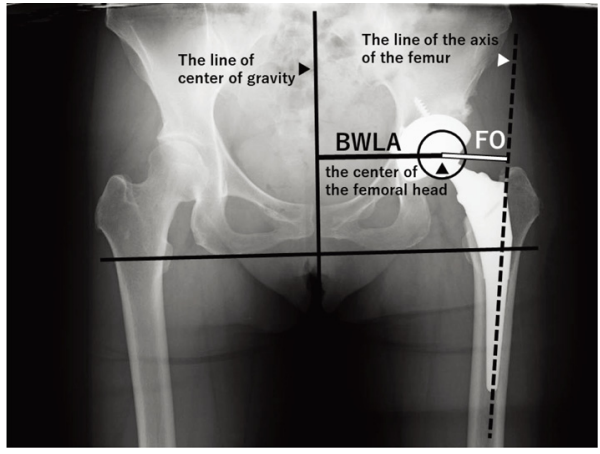

Fig. 2. Femoral offset and body weight lever arm The ratio of FO (white bar) and BWLA (solid bar) was calculated (FO \%).

type I and Crowe $0 \%$.

FO was measured postoperatively. FO was defined as the length of a perpendicular line from the line of the axis of the femur to the center of the femoral head of the prosthesis. The body-weight lever arm (BWLA) was defined as the distance from the center of the femoral head to the line of the center of gravity (Fig. 2). The ratio of FO and BWLA was calculated (FO \%).

$\mathrm{HC}$ was measured postoperatively. $\mathrm{HC}$ was defined as the length of a perpendicular line from the center of the femoral head of the prosthesis to the reference line connecting the inferior margin of each tear drop. The definition of a high hip center was $2 \mathrm{~cm}$ or more above the anatomical $\mathrm{HC}^{19}$.

Physical activities were measured by the $\mathrm{FAI}^{20,21)}$. Physical activities were defined as regular activities in the ADL setting 3 months before the onset of this study. The FAI evaluates the frequency and intensity of physical activities in the ADL setting. The FAI score ( $0-45$ points) ranges from 0 points for a sedentary life style to 45 points for a very active life style.

Home exercises were explained at the time of discharge. Patients were told to do home exercises and to complete the self-report sheet every day for 2 months after surgery. They were also asked to collect the self-report sheets at the end of the postoperative period ( 2 months after surgery). The compliance rate with exercises was calculated based on the performance of exercise sessions. Home exercises consisted of a 3-exercise menu: clamshell exercise, hip raise exercise, and hip abduction exercise. Each exercise session consisted of 1 set of 20 repetitions in the supine position.

Psychological status measurements of all patients were performed using the JHEQ mental score, a sub-scale of the $\mathrm{JHEQ}^{22}$, which is a self-administered questionnaire that can be useful in patients who frequently engage in deep flexion of the hip joint due to lifestyle and culture. The JHEQ mental score contains these question items: anxiety, irritation, dissatisfaction, and difficulty participating in activity or the local community.

Statistical analyses were conducted by a co-investigator (JA) who was independent from the recruitment, intervention, and data collection. The minimal sample size for the stepwise multiple regression analysis to examine significant factors $(\alpha=0.05$, power $=0.95$, effect size $=0.4$ ) was calculated. Additionally, assuming a $1 \%$ dislocation rate after THA, a $1 \%$ dropout rate was set; 66 participants were required.

Factors related to isometric hip abductor muscle strength 2 and 6 months after surgery were examined by stepwise multiple regression analysis. The dependent variable was isometric hip abductor muscle strength 2 and 6 months after surgery. Independent variables were age, BMI, disease duration, FO, Crowe \%, isometric hip abductor muscle strength in the preoperative period, compliance rate with home exercise at 2 months after surgery, FAI at 2 or 6 months after surgery, and the JHEQ mental score at 2 or 6 months after surgery. For all statistical tests, $\mathrm{p}<0.05$ was considered significant.

All data were analyzed using SPSS software (version 21, IBM, Chicago, IL, USA).

\section{RESULTS}

Six participants were unable to complete the study after surgery because of alteration of the surgical procedure $(\mathrm{n}=1)$, perioperative femoral fracture $(n=1)$, other limb fracture after surgery $(n=1)$, depression $(n=2)$, and did not attend follow-up examinations ( $\mathrm{n}=1)$; thus, 97 participants were included in the analysis (Table 1).

Femoral prostheses used included the M/L Taper with Kinectiv stem (straight neck: 56 , anteverted neck: 1, retroverted neck: 2) (Zimmer Warsaw, IN, USA) in 59 patients, a Trabecular metal primary hip prosthesis stem (Zimmer) in 22 patients, and an SL-PLUS stem (Smith \& Nephew Andover, MA, USA) in 16 patients. Femoral head diameter was $26 \mathrm{~mm}$ in 38 patients, $28 \mathrm{~mm}$ in 52 patients, $32 \mathrm{~mm}$ in 6 patients, and $36 \mathrm{~mm}$ in 1 patient. No patient had a high hip center. The height of the hip center was within $1.2 \mathrm{~cm}$ of the anatomical hip center in all patients. 
Table 1. Demographic data of the patients

\begin{tabular}{lc}
\hline Variable & mean $\pm \mathrm{SD}$ \\
\hline Number of patients & 97 \\
Age (years) & $62.2 \pm 8.4$ \\
Body mass index at pre-operative period $\left(\mathrm{kg} / \mathrm{m}^{2}\right)$ & $23.4 \pm 3.7$ \\
Diagnosis (secondly OA due to hip dysplasia: primary OA) & $94: 3$ \\
Co-morbidity Index (score) & $0.3 \pm 0.6$ \\
Disease duration (years) & $9.1 \pm 9.9$ \\
Crowe \% (amount of subluxation of the hip) & $21.1 \pm 2.1$ \\
Crowe class (type I: II: III: IV) & $75: 21: 1: 0$ \\
\hline
\end{tabular}

OA: osteoarthritis

Table 2. Chronological changes in the pre- and postoperative periods

\begin{tabular}{lccc}
\hline Evaluated measures & Preoperative period & $\begin{array}{c}\text { Postoperatively } \\
2 \text { months }\end{array}$ & $\begin{array}{c}\text { Postoperatively } \\
6 \text { months }\end{array}$ \\
\hline Harris Hip Score (point) & $60.5 \pm 12.9$ & $77.8 \pm 6.8$ & $86.9 \pm 6.5$ \\
Hip abductor muscle strength $(\mathrm{Nm} / \mathrm{kg})$ & $0.61 \pm 0.18$ & $0.72 \pm 0.19$ & $0.83 \pm 0.26$ \\
Femoral offset \% & & $43.9 \pm 7.2$ & \\
JHEQ mental score & $10.4 \pm 6.2$ & $16.9 \pm 6.6$ & $20.0 \pm 6.1$ \\
Frenchay Activities Index & $29.3 \pm 6.6$ & $23.3 \pm 7.3$ & $29.8 \pm 5.6$ \\
Compliance rate of home exercise & & $86.8 \pm 18.9$ & \\
\hline
\end{tabular}

Table 3. Factors related to hip abductor muscle strength at 2 months and 6 months after surgery

\begin{tabular}{lccc}
\hline Independent variable & $\begin{array}{c}\text { Standard partial } \\
\text { regression } \\
\text { coefficient }(\beta)\end{array}$ & $\mathrm{R}$ & $\mathrm{R}^{2}$ \\
\hline Included factors (2 months after surgery) & & & \\
$\quad$ Hip abductor muscle strength at preoperative period & 0.467 & 0.550 & $0.303 *$ \\
BMI & -0.291 & 0.607 & $0.369 *$ \\
JHEQ mental score at postoperatively 2 months & 0.212 & 0.643 & $0.413 *$ \\
Included factors (6 months after surgery) & & & $0.283 *$ \\
Hip abductor muscle strength at preoperative period & 0.443 & 0.532 & $0.364 *$ \\
BMI & -0.286 & 0.604 & $0.403 *$ \\
JHEQ mental score at postoperatively 6 months & 0.198 & 0.635 & \\
\hline
\end{tabular}

$* \mathrm{p}<0.05$

Chronological changes are shown in Table 2. Significant factors related to isometric hip abductor muscle strength at 2 months after surgery were, in extraction order: 1 . isometric hip abductor muscle strength in the preoperative period $(\beta=0.467$, $\mathrm{p}<0.05)$; 2. BMI $(\beta=-0.291, \mathrm{p}<0.05)$; and 3. JHEQ mental score at 2 months after surgery $(\beta=0.212, \mathrm{p}<0.05)($ Table 3$)$. Significant factors related to isometric hip abductor muscle strength at 6 months after surgery were, in extraction order: 1. isometric hip abductor muscle strength in the preoperative period $(\beta=0.443, \mathrm{p}<0.05) ; 2$. BMI $(\beta=-0.286, p<0.05)$; and 3. JHEQ mental score at 6 months after surgery $(\beta=0.198, \mathrm{p}<0.05)$ (Table 3). There was no variance inflation factor in the stepwise multiple regression analysis. In addition, Delp and Wixson ${ }^{19)}$ reported that a 2 -cm superior positioning of the hip center, without lateral placement, does not have major adverse effects on hip abductor muscle strength. Accordingly, this study did not examine the effect of $\mathrm{HC}$ on hip abductor muscle strength.

\section{DISCUSSION}

Previous reports on predicting hip abductor muscle strength after THA can be roughly classified into two types: reports related to lever arm, which is at the core of reconstructing hip function ${ }^{1-5)}$, and reports concerning preoperative physical function or demographic data ${ }^{6,11-16)}$. While there are many reports on factors involved in hip abductor muscle strength, there 
are no reports on the relationships among these factors, and in order to prevent the prolongation of decreased hip abductor muscle strength, it is necessary to elucidate which factors are involved in such prolongation and to preferentially address the issues pertaining to these factors.

In the present study, the same factors were related to hip abductor muscle strength at 2 months and at 6 months after surgery, and the order in which they were extracted was also the same. Preoperative hip abductor muscle strength was extracted as the most significant factor, while the postoperative compliance rate with exercise was not a significant factor. Jan and Hung ${ }^{23}$ conducted a 3-month study concerning postoperative voluntary training primarily involving antigravity exercise and walking, and they reported that functional improvements can be expected even at 18 months post-THA, as long as the compliance rate with exercise is $\geq 50 \%$ and the hip abductor muscle strength has improved. The compliance rate with exercise in the present study was high, at $86.8 \pm 18.9 \%$ at 2 months postoperatively; however, this was not extracted as a factor, possibly because exercise tasks were lower in load compared to previous studies. The present results also indicated that it is important to focus on muscle strengthening exercises from the preoperative stage in order to efficiently achieve postoperative hip abductor muscle strength. However, Rooks and Huang ${ }^{24}$ conducted a 6-week, pre-THA exercise therapy regimen primarily using muscle strength training machines ( $\sim 10 \mathrm{RM}$ : 10 times repetition maximum) and pool exercises, and they reported that, while the physical functioning score on the SF-36 improved, gross extensor muscle strength did not improve. Further investigations are necessary to identify a method to efficiently improve preoperative hip abductor muscle strength.

BMI was extracted as the second most significant factor. Obese patients needed higher torque of hip abductor muscle strength compared with thin patients because hip abductor muscle strength: torque and the body weight ratio were measured using the spina malleolar distance and body weight. This indicates that obese patients are at a disadvantage for gaining appropriate muscle strength. However, it may not be considered effective to encourage patients to lose weight before surgery.

The JHEQ mental score was extracted as the third most significant factor. It has been reported that depression after THA is involved in increased perioperative adverse events ${ }^{25)}$ and ADL limitations at two years postoperatively ${ }^{26)}$, and it increases the risk of early revision surgery ${ }^{27}$. It is postulated that the JHEQ mental score not only affects postoperative hip abductor muscle strength, but it also has a mutual relationship, in that a prolonged decrease in muscle strength affects the patients' mental state, such as self-efficacy ${ }^{28)}$. To intervene for the patients' mental state ${ }^{29,30)}$, it is important to encourage the patients' self-efficacy for activity and social participation through improving hip abductor muscle strength. Additionally, for patients who experience anxiety or frustration about postoperative living, it is necessary to establish initiatives to encourage self-efficacy, including peer counseling by patients who have previously undergone THA and do not experience problems in everyday life ${ }^{31)}$.

Contrary to the authors' expectations, FO was not extracted as a factor affecting postoperative hip abductor muscle strength. Tezuka and Inaba ${ }^{32)}$ reported that increasing FO together with shifting the hip center medially and distally is effective in hip abductor muscle strength recovery. In contrast, Bjørdal and Bjørgul ${ }^{33)}$ reported that increased FO did not affect hip function, consistent with the present findings. At 2 months after surgery in the present study, the standard deviation of the mean was smaller for FO than for hip abductor muscle strength (16.4\% vs. 26.4\%). From this perspective, it is postulated that FO was not extracted as an influencing factor because FO was constructed with consideration of its effects on hip abductor muscle strength, resulting in such effects becoming homogeneous.

The limitations of this study are as follows. First, preoperative femoral neck anteversion was not measured. However, of the study patients, $77.3 \%$ had Crowe class I, $21.6 \%$ had type II, and only one patient had type III. The Kinectiv was used in patients with dysplasia, a condition in which anteversion anomaly is a concern. A retroverted neck was used in patients with excessive anteversion, only 2 cases (2/59), and a straight neck was used in the majority of patients. Based on this information, the differences between each patient in neck anteversion after THA probably had a minimal effect on postoperative hip abductor muscle strength. Second, compliance rates with home exercise were checked by the self-report sheet; postoperative exercises after discharge were not performed under the supervision of a physical therapist in the present study.

As conclusion, the effects of FO, as well as preoperative and postoperative factors, on hip abductor muscle strength were investigated during the first 6 months after THA. The same factors were related to hip abductor muscle strength at 2 months and 6 months after surgery, and the order of extraction was: 1. preoperative hip abductor muscle strength; 2 . BMI; and 3. JHEQ mental score. FO was not extracted as a significant factor related to postoperative isometric hip abductor strength.

\section{REFERENCES}

1) McGrory BJ, Morrey BF, Cahalan TD, et al.: Effect of femoral offset on range of motion and abductor muscle strength after total hip arthroplasty. J Bone Joint Surg Br, 1995, 77: 865-869. [Medline]

2) Delp SL, Maloney W: Effects of hip center location on the moment-generating capacity of the muscles. J Biomech, 1993, 26: 485-499. [Medline] [CrossRef]

3) Vasavada AN, Delp SL, Maloney WJ, et al.: Compensating for changes in muscle length in total hip arthroplasty. Effects on the moment generating capacity of the muscles. Clin Orthop Relat Res, 1994, (302): 121-133. [Medline]

4) Kiyama T, Naito M, Shitama H, et al.: Effect of superior placement of the hip center on abductor muscle strength in total hip arthroplasty. J Arthroplasty, 2009, 24: 240-245. [Medline] [CrossRef]

5) Asayama I, Chamnongkich S, Simpson KJ, et al.: Reconstructed hip joint position and abductor muscle strength after total hip arthroplasty. J Arthroplasty, 
2005, 20: 414-420. [Medline] [CrossRef]

6) Arokoski MH, Arokoski JP, Haara M, et al.: Hip muscle strength and muscle cross sectional area in men with and without hip osteoarthritis. J Rheumatol, 2002, 29: 2185-2195. [Medline]

7) Bertocci GE, Munin MC, Frost KL, et al.: Isokinetic performance after total hip replacement. Am J Phys Med Rehabil, 2004, 83: 1-9. [Medline] [CrossRef]

8) Reardon K, Galea M, Dennett X, et al.: Quadriceps muscle wasting persists 5 months after total hip arthroplasty for osteoarthritis of the hip: a pilot study. Intern Med J, 2001, 31: 7-14. [Medline] [CrossRef]

9) Sicard-Rosenbaum L, Light KE, Behrman AL: Gait, lower extremity strength, and self-assessed mobility after hip arthroplasty. J Gerontol A Biol Sci Med Sci, 2002, 57: M47-M51. [Medline] [CrossRef]

10) Liu R, Wen $X$, Tong $Z$, et al.: Changes of gluteus medius muscle in the adult patients with unilateral developmental dysplasia of the hip. BMC Musculoskelet Disord, 2012, 13: 101. [Medline] [CrossRef]

11) Slaven EJ: Prediction of functional outcome at six months following total hip arthroplasty. Phys Ther, 2012, 92: 1386-1394. [Medline] [CrossRef]

12) Santaguida PL, Hawker GA, Hudak PL, et al.: Patient characteristics affecting the prognosis of total hip and knee joint arthroplasty: a systematic review. Can J Surg, 2008, 51: 428-436. [Medline]

13) Suetta C, Aagaard P, Magnusson SP, et al.: Muscle size, neuromuscular activation, and rapid force characteristics in elderly men and women: effects of unilateral long-term disuse due to hip-osteoarthritis. J Appl Physiol 1985, 2007, 102: 942-948. [Medline] [CrossRef]

14) van Baar ME, Dekker J, Lemmens JA, et al.: Pain and disability in patients with osteoarthritis of hip or knee: the relationship with articular, kinesiological, and psychological characteristics. J Rheumatol, 1998, 25: 125-133. [Medline]

15) Vissers MM, Bussmann JB, Verhaar JA, et al.: Psychological factors affecting the outcome of total hip and knee arthroplasty: a systematic review. Semin Arthritis Rheum, 2012, 41: 576-588. [Medline] [CrossRef]

16) Vissers MM, Bussmann JB, Verhaar JA, et al.: Recovery of physical functioning after total hip arthroplasty: systematic review and meta-analysis of the literature. Phys Ther, 2011, 91: 615-629. [Medline] [CrossRef]

17) Berger RA: Mini-incision total hip replacement using an anterolateral approach: technique and results. Orthop Clin North Am, 2004, 35: 143-151. [Medline] [CrossRef]

18) Crowe JF, Mani VJ, Ranawat CS: Total hip replacement in congenital dislocation and dysplasia of the hip. J Bone Joint Surg Am, 1979, 61: 15-23. [Medline] [CrossRef]

19) Delp SL, Wixson RL, Komattu AV, et al.: How superior placement of the joint center in hip arthroplasty affects the abductor muscles. Clin Orthop Relat Res, 1996, (328): 137-146. [Medline] [CrossRef]

20) Wade DT, Legh-Smith J, Langton Hewer R: Social activities after stroke: measurement and natural history using the Frenchay Activities Index. Int Rehabil Med, 1985, 7: 176-181. [Medline] [CrossRef]

21) Schuling J, de Haan R, Limburg M, et al.: The Frenchay Activities Index. Assessment of functional status in stroke patients. Stroke, 1993, 24: 1173-1177. [Medline] [CrossRef]

22) Matsumoto T, Kaneuji A, Hiejima Y, et al. The Subcommittee on Hip Disease Evaluation of the Clinical Outcome Committee of the Japanese Orthopaedic Association: Japanese Orthopaedic Association Hip Disease Evaluation Questionnaire (JHEQ): a patient-based evaluation tool for hip-joint disease. J Orthop Sci, 2012, 17: 25-38. [Medline] [CrossRef]

23) Jan MH, Hung JY, Lin JC, et al.: Effects of a home program on strength, walking speed, and function after total hip replacement. Arch Phys Med Rehabil, 2004, 85: 1943-1951. [Medline] [CrossRef]

24) Rooks DS, Huang J, Bierbaum BE, et al.: Effect of preoperative exercise on measures of functional status in men and women undergoing total hip and knee arthroplasty. Arthritis Rheum, 2006, 55: 700-708. [Medline] [CrossRef]

25) Buller LT, Best MJ, Klika AK, et al.: The influence of psychiatric comorbidity on perioperative outcomes following primary total hip and knee arthroplasty; a 17-year analysis of the National Hospital Discharge Survey database. J Arthroplasty, 2015, 30: 165-170. [Medline] [CrossRef]

26) Singh JA, Lewallen DG: Predictors of activity limitation and dependence on walking aids after primary total hip arthroplasty. J Am Geriatr Soc, 2010, 58: 2387-2393. [Medline] [CrossRef]

27) Bozic KJ, Lau E, Ong K, et al.: Risk factors for early revision after primary total hip arthroplasty in Medicare patients. Clin Orthop Relat Res, 2014, 472: 449-454. [Medline] [CrossRef]

28) Conn VS: Older adults and exercise: path analysis of self-efficacy related constructs. Nurs Res, 1998, 47: 180-189. [Medline] [CrossRef]

29) Bandura A, Cervone D: Self-evaluative and self-efficacy mechanisms governing the motivational effects of goal systems. J Pers Soc Psychol, 1983, 45: 1017-1028. [CrossRef]

30) Bandura A, Reese L, Adams NE: Microanalysis of action and fear arousal as a function of differential levels of perceived self-efficacy. J Pers Soc Psychol, 1982, 43: 5-21. [Medline] [CrossRef]

31) Dures E, Almeida C, Caesley J, et al.: Patient preferences for psychological support in inflammatory arthritis: a multicentre survey. Ann Rheum Dis, 2016, 75: 142-147. [Medline] [CrossRef]

32) Tezuka T, Inaba Y, Kobayashi N, et al.: Effects of hip joint center location and femoral offset on abductor muscle strength after total hip arthroplasty. Mod Rheumatol, 2015, 25: 630-636. [Medline] [CrossRef]

33) Bjørdal F, Bjørgul K: The role of femoral offset and abductor lever arm in total hip arthroplasty. J Orthop Traumatol, 2015, 16: 325-330. [Medline] [CrossRef] 